\title{
Expression of SOX2 in oral squamous cell carcinoma and the association with lymph node metastasis (Review)
}

\author{
ZHEN-HU REN ${ }^{1,2}$, CHEN-PING ZHANG $^{1}$ and TONG JI ${ }^{1}$ \\ ${ }^{1}$ Department of Oral and Maxillofacial-Head and Neck Oncology, Ninth People's Hospital, \\ Shanghai Jiao Tong University School of Medicine, Shanghai 200011; ${ }^{2}$ Department of Oral and Maxillofacial Surgery, \\ The Second Xiangya Hospital of Central South University, Changsha, Hunan 410011, P.R. China
}

Received February 7, 2015; Accepted December 18, 2015

DOI: $10.3892 / \mathrm{ol} .2016 .4207$

\begin{abstract}
Oral squamous cell carcinomas (OSCCs) are a growing problem in the world. The various existing treatments have not markedly improved the survival rate of patients with OSCC during the past three decades. Novel treatment strategies are required. Sex determining region Y-box 2 (SOX2) is a transcription factor that is involved in the maintenance of embryonic stem cell pluripotency and in multiple developmental processes. SOX2 expression was indicated to act as a prognostic factor in various types of tumors, including breast, colorectal, gastric and lung cancer and glioblastoma, and as a link between malignancy and stemness. Cancer stem cells (CSCs) may be responsible for the genesis, growth and metastatic spread of tumors. The poor survival outcomes for OSCC patients may be attributable to a poor selection of target cells for treatment, as current oral cancer therapies are generally aimed at the global mass of tumor. Therefore, the consideration that novel approaches to oral cancer may be targeted using SOX2 and CSCs appears reasonable. In order to better understand the oncogenic roles and the corresponding signal transduction pathways of the SOX2 protein, the present study emphasizes the role of SOX 2 in OSCC, including the proteins associated with OSCC, and reviews the literature regarding the role of SOX2 in lymph node metastasis. The aim of the present study is to provide a reference for future studies that engage in research on the aforementioned subject.
\end{abstract}

\section{Contents}

1. Introduction

2. Expression of SOX2 in OSCC

3. Association between SOX2 and lymph node metastasis

Correspondence to: Professor Chen-Ping Zhang, Department of Oral and Maxillofacial-Head and Neck Oncology, Ninth People's Hospital, Shanghai Jiao Tong University School of Medicine, 639 Zhizaoju Road, Shanghai 200011, P.R. China

E-mail: zhangcp9th@hotmail.com

Key words: oral cancer, lymph node metastasis, SOX2, cancer stem cell

\section{Introduction}

Sex determining region Y-box 2 (SOX2) is a transcription factor that is involved in the maintenance of embryonic stem cell pluripotency and in multiple developmental processes $(1,2)$. Increasing numbers of studies regarding the association between SOX2 and malignant tumors have been reported. Numerous studies have indicated that SOX2 is involved in in tumorigenesis, including in skin squamous cell carcinoma, gastric cancer, glioblastoma, colorectal cancer, lung cancer and breast cancer (3-8). SOX2 has demonstrated a pro-oncogenic function in the majority of the various types of malignant tumor, including breast, colorectal and lung cancer and glioblastoma, but not gastric cancer. The expression of SOX2 in oral squamous cell carcinomas (OSCC) has also been reported, and SOX2 nuclear expression is closely associated with a poor prognosis in oral tongue squamous cell carcinoma (OTSCC) (9). In addition, the increased expression of SOX2 in OSCC is associated with lymph node metastasis (10).

Oral cancer is a growing problem in the world and demonstrates a high prevalence among men in Asia, particularly in India, as oral cancer is the most prevalent type of cancer in Indian men (11-13). The overall 5-year survival rate of patients following a surgical resection or other treatment has not markedly improved during the past three decades, and remains at $\sim 50 \%$ (14). The presence of lymph node metastasis is considered to be an important indicator of predicting an adverse outcome $(15,16)$. However, certain OSCC patients that do not possess node metastasis continue to suffer from tumor relapses subsequent to complete surgical resections, and then poor prognoses $(9,17)$. Novel treatment strategies are required. In previous studies, SOX2 has been indicated to act as a prognostic factor in various types of tumors and as a link between malignancy and stemness $(3,18,19)$. Novel studies indicate that cancer stem cells (CSCs) may be responsible for the genesis, growth and metastatic spread of the tumor $(20,21)$. The poor survival outcomes for OSCC patients may be attributable to a poor selection of target cells for treatment, as current oral cancer therapies are generally aimed at the overall mass of the tumor. Therefore, the consideration that novel approaches to oral cancer may be targeted using SOX2 and CSCs appears reasonable. 
In order to better understand the oncogenic roles and corresponding signal transduction pathways of the SOX2 protein, the present study emphasizes the role of SOX 2 and the associated proteins in OSCC, and reviews the literature on the role of SOX2 in lymph node metastasis. The aim of the present study is to provide a reference for future studies that engage in research on the aforementioned subject.

\section{Expression of SOX2 in OSCC}

SOX2 is an amplified gene in OSCC, which is established as one of the hallmark participants throughout the developmental process in cancer. SOX 2 is mainly expressed in CSCs. In order to study the role of SOX 2 in OSCC, the concept and identification of CSC must be understood.

Concept and identification of CSCs. The major characteristic that defines stem cells is self-renewal, whereby stem cells result in numerous types of mature cells and lead to organogenesis (22). Similar cells that exist in cancer, termed CSCs, have been previously documented (22). In addition to the ability to self-renew, CSCs may result in phenotypically varied tumor cell populations through a process of aberrant differentiation. CSCs may, therefore, be responsible for driving tumorigenesis and tumor growth. The theory that tumorigenesis is based exclusively on the aberrant activity of CSCs derives from the heterogeneous nature of OSCCs and other tumors (23). The structural similarity of well-differentiated tumors with the epithelium of origin may also confirm the existence of CSCs. In particular, a well-differentiated OSCC may reproduce the proliferation pattern and histological appearance of the oral epithelium. Due to the lack of reliable specific markers of CSCs (24), there are numerous unresolved issues regarding OSCCs (25).

Numerous distinct models attempt to explain the origin of CSCs. The most important hypothesis regarding the origin of CSCs is that they develop from the transformation of stem cells (SCs). This hypothesis is compelling for several reasons. The malignant transformation of a normal cell requires 3-6 oncogenic events, and the long life of SCs increases the risk of accumulating the multiple mutations (26). SCs and CSCs possessing the capacity for self-renewal is an additional reason to consider that the origin of CSCs is normal SCs, as the dysregulation of the self-renewal process is an early and important event in carcinogenesis. Although the hypothesis that CSCs derive from normal adult SCs appears to be the most plausible, other origins may also be possible. A CSC may originate from the fusion of a hemopoietic stem cell (HSC) with a mutated epithelial somatic cell. In 2004, Wagers and Weissman and Houghton et al demonstrated that the fusion of HSCs with epithelial cells has been shown in vitro and in vivo in animal models of stomach cancer $(27,28)$. At present, the fusion of HSCs with epithelial cells has not been demonstrated in OSCC. A CSC may also result from the de-differentiation of a mature cell (29). Previous studies demonstrate that differentiated cancer cells may achieve a CSC-like state through epithelial mesenchymal transition (EMT). EMT is involved in the acquisition by differentiated cells of the properties of SCs, including in nasopharyngeal (30), breast (31) and head and neck squamous cell carcinomas (HNSCC) (32). A sparsely proliferative basal layer with highly proliferative parabasal cell layers in premalignant epithelia is another frequently observed proliferation pattern. The aforementioned observation may indicate that the tumor did not originate exclusively from a normal basal SC, but also from an amplifying transitory cell (33).

The scarcity of markers for identifying CSCs restricts the knowledge that studies may gain regarding the role of CSCs in carcinogenesis; therefore, the perfect identification technique does not yet exist. The most frequently applied method for identifying CSCs is flow cytometry, which detects cells with the ability to excrete the vital DNA dye Hoechst 33342 (34-38). A distinctive small non-dyed population of cells, termed the side population (SP), has been detected in numerous tumors, and is highly tumorigenic (39-44). SP cells express SCs markers, including cluster of differentiation (CD)44 (45), ATP-binding cassette sub-family G member 2 (44), octamer-binding transcription factor (Oct)4 (35) and B cell-specific Moloney murine leukemia virus integration site 1 proto-oncogene (45). The SP population ranges between $0.2-10.0 \%$ of the cancer cell population (35). Flow cytometry does not permit CSCs to be topographically localized in healthy or tumorous tissues for the assessment of proliferative activity or spatial associations with progeny. The transcription factors SOX2 $(46,47)$, Oct3/4 (45), $\beta$-1 integrin (48), CD133 (49) and CD44 (50) demonstrate promise for the topographical localization of CSCs. The transcription factors SOX2 and Oct3/4 are essential for maintaining the self-renewal capacity and pluripotency of embryonic and adult SCs. CD133+ cells in OSCC form holoclones and possess self-renewal capacity (51), and CD44+ cells in HNSCC possess the capacity for self-renewal and differentiation (52). However, the usefulness of CD44 as a marker of CSCs in OSCC is questionable as CD44 is expressed by normal oral epithelial cells $(53,54)$. The value of CD44 as a marker of OSCC progression and prognosis is also controversial. Certain studies in HNSCC have reported aldehyde dehydrogenase $(\mathrm{ALDH})^{+}$cells with typical CSC behavior, in particular the tumorigenic ability (55-58). The specificity of CD44 as a marker of CSCs in HNSCC is reported to be increased in combination with ALDH $(55,56)$. Although a small number of $\mathrm{ALDH}^{+} / \mathrm{CD} 44^{-} \mathrm{CSC}$ exist (56). In addition, E-cadherin, CD97, CD117, CD147, CK19 and epithelial-specific antigen have been used in attempts to identify oral SCs/CSCs; however the antigens were not adequately specific (59-62). Notably, Miranda-Lorenzoan et al identified an intrinsic autoflorescent phenotype in CSCs from diverse epithelial cancers, and used the marker to isolate and characterize the CSCs (63).

SOX2 in OSCC. SOX2 is an important stem cell marker that is crucial for embryonic development and to maintain the differentiation potential of stem cells. SOX2 is one of the key transcription factors involved in inducing pluripotent stem cells. In the past decade, SOX2 has been established as one of the hallmark participants of the developmental process in cancer, including in skin squamous cell carcinoma, gastric cancer, glioblastoma, colorectal cancer, lung cancer, breast cancer and OSCC (3-9).

SOX2 is an amplified gene in OSCC, and the key role of $\mathrm{SOX} 2$ is to maintain the stemness of the cells. Nadja et al demonstrated that SOX2 amplifications are common in OSCC 
and the detection of SOX2 amplifications in the early stages of disease may be crucial for early disease detection and a more accurate prognosis (64). He et al revealed that the expression of SOX2 was amplified in OSCC and was significantly associated with the pathological grade (65). In addition, a significant difference in SOX2 staining was demonstrated between OSCC, oral epithelial dysplasia and normal oral mucosa. Previous studies showed that SOX2 was overexpressed in OSCCs, the expression of SOX2 was decreased in the CAL27 and UMSCC74A cell lines that were treated with cationic lipid nanoparticles to deliver pre-miR-107, and the tumorsphere formation efficiency and size were decreased (66-68). However, the mechanism by which miR-107 regulates SOX2 expression in HNSCC is unclear. Studies indicate that SOX2 is amplified in numerous types of tumors, which is associated with the indicators of a favorable prognosis (69). SOX2 overexpression has been demonstrated to deregulate genes in malignant processes, cellular migration and anchorage-independent growth (70).

SOX2 performs a similar role in CSCs to that in embryonic stem cells. In a previous study, SOX2 was preferentially expressed in cancer cells with a basal-like phenotype, and is, therefore, likely to contribute to defining the characteristics of less differentiated stem cell phenotypes (71). A similar phenomenon existed in studies on OSCCs and HNSCCs, as SOX2 was mainly expressed in the stratum basale, co-localizing with the region that contained stem cells $(68,72)$. In addition to the application of SOX2 in identifying various subsets of tumor cells, SOX2 also maintains the stemness of tumor-initiating cells (TICs) and CSCs.

In a previous study, SOX2 knockdown in CSCs led to the inhibition of proliferation and loss of tumorigenicity in immunodeficient mice, indicating that SOX2 was crucial for maintaining the self-renewal capacity of CSCs (73). The role of SOX2 in maintaining the self-renewal capacity of CSCs in HNSCC and breast cancer has been previously confirmed $(74,75)$. The findings of these studies indicate that SOX2 expression promotes and maintains the stemness of CSCs. Other important roles of SOX2 in cancer progression include the contribution to the physiological or pathophysiological process of cancer cells. The proliferation of HNSC CSCs was inhibited in vitro and in vivo, as SOX2 was suppressed by all-trans-retinoic acid (76). SOX2 expression has been demonstrated to improve the ability of invasion and migration of tumor cells in tongue squamous cell carcinoma (TSCC) (77). Other properties of cancer cells in OSCC or HNSCC that involve the SOX2 protein include apoptosis $(74,78)$, chemoresistance (79), metastasis and tumorigenesis $(10,79)$.

SOX2 is a key regulator of development and carcinogenesis and exhibited close associations with several microRNAs. In a previous study, the activities of SOX 2 were indicated to be controlled by numerous microRNAs; therefore, certain microRNAs may also be regulated by SOX2, including microRNA-145 (80,81), microRNA-107 (67) and microRNA-302 (74). Bourguignon et al demonstrated that the stimulation of miR-302 expression by hyaluronan-CD44 is Oct4-SOX2-Nanog-dependent in HNSCC-specific CSCs, and that microRNA-302 expression was the underlying mechanism of self-renewal, clonal formation and cisplatin resistance in CSCs in HNSCC (74). The roles of SOX2 in cancers are summarized in Fig. 1.

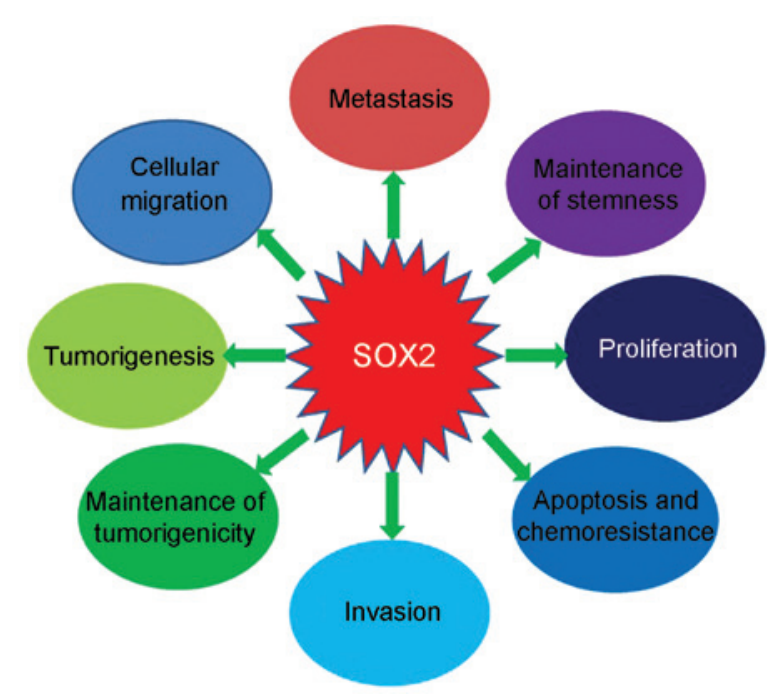

Figure 1. The SOX2 protein affects numerous processes of cancer cells. SOX2, Sex determining region Y-box 2.

At present, several studies have revealed that SOX2 overexpression in cancer cells exhibited a deleterious outcome, and resulted in lower survival rates of patients. Several studies have revealed that the SOX2 proteins were overexpressed in the TSCC, and demonstrated that SOX2, recurrence and distant metastasis were independent prognostic factors of overall survival in patients with TSCC. Therefore the studies concluded that the expression of SOX 2 may be used as a prognostic indicator of TSCC (82). SOX2 was exclusively expressed in the CSCs of OSCC patients and the expression of SOX2 was significantly associated with a poor prognosis of OSCC and lymph node status, which indicates the potential prognostic value of SOX2 in OSCC. SOX2 may also act as a promising marker for directing OSCC diagnosis and therapy (65). The evidence that SOX2 overexpression was oncogenic was also demonstrated in HNSCC patients, and SOX2 was indicated to be associated with a worse prognosis. These findings are valuable in providing useful information for developing a novel classification system and therapeutic strategies for HNSCC (64). However, the opposite viewpoint from certain studies supported that increased levels of SOX2 was significantly associated with better prognosis in the patients of OSCC and squamous cell lung cancer $(69,79)$.

SOX2 was amplified in numerous types of cancer, including OSCC. However, the role of SOX2 in cancer is controversial. The vast majority of studies show that SOX2 overexpression may promote cancer progression, hypothesizing that SOX2 may act as a potential target for cancer therapy. However, certain studies hypothesized that SOX2 may suppress tumors and that SOX 2 overexpression inhibits the cell proliferation. In addition, the opposite views of the association between SOX2 and the survival rate of patient were stated in other studies. The vast majority of studies showed that the survival rate of OSCC patients possessing low levels of SOX2 is increased compared with those with high levels of SOX2. However, the opposite view was indicated by Züllig et al, who supported that low level SOX2 expression was significantly associated with worse survival (79). Additional studies are required in order to understand the conflicting opinions. In conclusion, the 
overexpression of SOX2 derived from amplification promotes cancer progression and tumor formation. SOX2 may provide a novel diagnostic marker for OSCC, be used as a therapeutic stratification marker, or target molecules for therapeutic interference; however, the underlying molecular mechanism remains unclear (83).

\section{Association between SOX2 and lymph node metastasis}

Tumor metastasis is the key factor that compromises the prognosis of tumor patients, which accounts for $90 \%$ of tumor-associated mortalities $(84,85)$. Metastasis is a multistep process by which a percentage of primary tumor cells acquire the ability to spread between the initial site and secondary tissues or organs, or the surrounding normal tissues (86-88). Failure at any stage may restrict the entire metastatic process. Since metastasis is responsible for the majority of mortalities of cancer patients, an improved understanding of the molecular mechanism involved in the tumor spreading process is crucial for preventing tumor metastasis and improving the prognosis of patients.

SOX2 has recently been shown to be a putative CSC marker in several malignancies, including glioblastoma (5) and gastric (3), colorectal (6), breast (8), oral (9) and lung $(7,89)$ cancers. In addition, the importance of SOX2 in cancer metastasis has also been addressed. Previously, several studies demonstrated that SOX2 expression was closely associated with lymph node metastasis, distant spread and poor prognosis in colorectal carcinoma patients $(6,90,91)$. Certain data suggested that SOX2 knockdown may induce mesenchymal-epithelial transition (MET). MET is the reverse process of EMT. Epithelial cells gain polarity and motility during EMT, which are necessary for tumor invasion and metastasis in various types of epithelial carcinomas. Notably, studies have identified that knocking down SOX2 promoted MET and resulted in the translocation of $\beta$-catenin, which is critical in the WNT pathway (92). Studies indicated that all SOX2-positive primary tumors retained a SOX2-expressing phenotype during lymph node metastasis. This finding may indicate that SOX2-bearing cancer cells have an increased probability and ability to metastasize to the lymph node and supports the notion that SOX2 is crucial for breast cancer invasiveness and spread. Notably, a significantly increased SOX2 expression in lymph node metastasis compared with respective primary tumors was indicated (93). A similar finding was also reported in the study conducted by Lengerke et al, in which the data suggest that SOX2 is important in early breast carcinogenesis and that increased expression may promote metastatic potential (8). Downregulation of SOX2 significantly decreased angiogenesis and lymphomagenesis of breast cancer. Additionally, the promotion effect of SOX2 on tumor cell metastasis was observed in vitro and in the tumor bearing mice in vivo. SOX2 also promoted the EMT process in the tumor cells in breast cancer by regulating the WNT/ $\beta$-catenin signal pathway $(94,95)$. A previous study on lung cancer indicated that the overexpression of SOX2 was also positively associated with the tumor-node-metastasis stage and lymph node metastasis (96).

SOX2 protein expression was indicated to be significantly associated with lymph node metastasis and recurrence in
HNSCC patients (97). However, in numerous HNSCC patients, SOX2 expression was not associated with disease stage, lymph node metastasis or distant metastasis $(98,99)$. The contradictory results may be associated with methodological variations in the SOX2 immunopositivity scoring (99). Therefore, additional studies on the oncogenic function of SOX2 in HNSCC and the underlying molecular mechanisms accounting for the association of SOX2 with progression remain to be elucidated.

Similarly to HNSCC, the studies on the association between SOX2 and lymph node metastasis in OSCC are inadequate. Certain data showed that the SOX2 may be classified into diffuse staining patterns and peripheral staining patterns, and that the SOX2 diffuse staining pattern was associated with lymph node metastasis of OSCC (10). Even in OTSCCs without lymph node metastasis, SOX2 expression has been demonstrated to be involved in tumor progression (9). An additional study indicated that the poor prognosis associated with lymph node metastasis was significantly associated with the high expression of SOX2 in the primary sites of OSCCs (10). Qiao et al supported the finding that SOX2 expression was significantly associated with lymph node metastasis (100). However, the study conducted by Züllig et al showed that increased expression levels of SOX2 were significantly associated with a lack of lymph node metastasis, which implies a good prognosis in OSCC patients, and indicated that the heterogeneity of primary tumors may be one of the reasons for controversial results (79). This result is consistent with certain findings in lung cancer (101). According to the data in the study by Züllig et al, SOX2 is a potential predictive marker for the lack of metastasis to the sentinel lymph nodes of the neck in early SCC of the oral cavity (79).

Overall, based on the phenomenon of overexpression of SOX2 in several types of cancer and the role of SOX2 in promoting cancer progression, the application of SOX2 is hypothesized to aid decisions on cancer diagnosis and therapy, and may even predict the prognosis of patients. However, underlying molecular mechanisms of SOX2 in OSCC remain to be elucidated. The association between the expression of SOX2 in OSCC and lymph node metastasis is remains unclear. The molecular mechanisms underlying the association between SOX2 and lymph node metastasis require additional studies.

\section{References}

1. Ivanova N, Dobrin R, Lu R, Kotenko I, Levorse J, DeCoste C, Schafer X, Lun Y and Lemischka IR: Dissecting self-renewal in stem cells with RNA interference. Nature 442: 533-538, 2006.

2. Wang J, Rao S, Chu J, Shen X, Levasseur DN, Theunissen TW and Orkin SH: A protein interaction network for pluripotency of embryonic stem cells. Nature 444: 364-368, 2006.

3. Boumahdi S, Driessens G, Lapouge G, Rorive S, Nassar D, Le Mercier M, Delatte B, Caauwe A, Lenglez S, Nkusi E, et al: SOX2 controls tumour initiation and cancer stem-cell functions in squamous-cell carcinoma. Nature 511: 246-250, 2014.

4. Power DG, Kelsen DP and Shah MA: Advanced gastric cancer - slow but steady progress. Cancer Treat Rev 36: 384-392, 2010.

5. Koyama-Nasu R, Haruta R, Nasu-Nishimura Y, Taniue K, Katou Y, Shirahige K, Todo T, Ino Y, Mukasa A, Saito N, et al: The pleiotrophin-ALK axis is required for tumorigenicity of glioblastoma stem cells. Oncogene 33: 2236-2244, 2014.

6. Neumann J, Bahr F, Horst D, Kriegl L, Engel J, Luque RM, Gerhard M, Kirchner T and Jung A: SOX2 expression correlates with lymph-node metastases and distant spread in right-sided colon cancer. BMC Cancer 11: 518, 2011. 
7. Drilon A, Rekhtman N, Ladanyi M and Paik P: Squamous-cell carcinomas of the lung: Emerging biology, controversies, and the promise of targeted therapy. Lancet Oncol 13: e418-e426, 2012 .

8. Lengerke C, Fehm T, Kurth R, Neubauer H, Scheble V, Müller F, Schneider F, Petersen K, Wallwiener D, Kanz L, et al: Expression of the embryonic stem cell marker SOX2 in early-stage breast carcinoma. BMC Cancer 11: 42, 2011.

9. Du L, Yang Y, Xiao X, Wang C, Zhang X, Wang L, Zhang X, Li W, Zheng G, Wang S and Dong Z: SOX2 nuclear expression is closely associated with poor prognosis in patients with histologically node-negative oral tongue squamous cell carcinoma. Oral Oncol 47: 709-713, 2011.

10. Michifuri Y, Hirohashi Y, Torigoe T, Miyazaki A, Kobayashi J, Sasaki T, Fujino J, Asanuma H, Tamura Y, Nakamori K, et al: High expression of ALDH1 and SOX2 diffuse staining pattern of oral squamous cell carcinomas correlates to lymph node metastasis. Pathol Int 62: 684-689, 2012.

11. Bray F, Ren JS, Masuyer E and Ferlay J: Global estimates of cancer prevalence for 27 sites in the adult population in 2008 . Int J Cancer 132: 1133-1145, 2013.

12. Ren ZH, Wu HJ, Zhang S, Wang K, Gong ZJ, He ZJ, Peng J: A new surgical strategy for treatment of tongue squamous cell carcinoma based on anatomic study with preliminary clinical evaluation. J Craniomaxillofac Surg 43: 1577-1582, 2015.

13. Ren ZH, Wu HJ, Wang K, Zhang S, Tan HY, Gong ZJ: Anterolateral thigh myocutaneous flaps as the preferred flaps for reconstruction of oral and maxillofacial defects. J Craniomaxillofac Surg 42: 1583-1589, 2014.

14. Brinkman BM and Wong DT: Disease mechanism and biomarkers of oral squamous cell carcinoma. Curr Opin Oncol 18: 228-233, 2006.

15. Guo BH, Feng Y, Zhang R, Xu LH, Li MZ, Kung HF, Song LB and Zeng MS: Bmi-1 promotes invasion and metastasis, and its elevated expression is correlated with an advanced stage of breast cancer. Mol Cancer 10: 10, 2011

16. Ren ZH and Wu HJ. Extracapsular spread in cervical lymph nodes. Shiyong Kou Qiang Yi Xue Za Zhi 28: 514-517, 2012 (In Chinese)

17. El-Naaj IA, Leiser Y, Shveis M, Sabo E and Peled M: Incidence of oral cancer occult metastasis and survival of T1-T2N0 oral cancer patients. J Oral Maxillofac Surg 69: 2674-2679, 2011.

18. Bass AJ, Watanabe H, Mermel CH, Yu S, Perner S, Verhaak RG, Kim SY, Wardwell L, Tamayo P, Gat-Viks I, et al: SOX2 is an amplified lineage-survival oncogene in lung and esophageal squamous cell carcinomas. Nat Genet 41: 1238-1242, 2009.

19. Kitamura H, Torigoe T, Hirohashi Y, Asanuma H, Inoue R, Nishida S, Tanaka T, Fukuta F, Masumori N, Sato N and Tsukamoto T: Prognostic impact of the expression of ALDH1 and SOX2 in urothelial cancer of the upper urinary tract. Mod Pathol 26: 117-124, 2013

20. Teodorczyk M, Kleber S, Wollny D, Sefrin JP, Aykut B, Mateos A, Herhaus P, Sancho-Martinez I, Hill O, Gieffers C, et al: CD95 promotes metastatic spread via Sck in pancreatic ductal adenocarcinoma. Cell Death Differ 22: 1192-1202, 2015.

21. Goel HL, Gritsko T, Pursell B, Chang C, Shultz LD, Greiner DL, Norum JH, Toftgard R, Shaw LM, Mercurio AM: Regulated splicing of the $\alpha 6$ integrin cytoplasmic domain determines the fate of breastcancer stem cells. Cell Rep 7: 747-761, 2014.

22. Reya T, Morrison SJ, Clarke MF and Weissman IL: Stem cells, cancer, and cancer stem cells. Nature 414: 105-111, 2001.

23. Pardal R, Clarke MF and Morrison SJ: Applying the principles of stem-cell biology to cancer. Nat Rev Cancer 3: 895-902, 2003

24. González-Moles MA, Scully C, Ruiz-Ávila I and Plaza-Campillo JJ: The cancer stem cell hypothesis applied to oral carcinoma. Oral Oncol 49: 738-746, 2013.

25. Boman BM and Wicha MS: Cancer stem cells: A step toward the cure. J Clin Oncol 26: 2795-2799, 2008.

26. Hahn WC and Weinberg RA: Rules for making human tumor cells. N Engl J Med 347: 1593-1603, 2002.

27. Wagers AJ and Weissman IL: Plasticity of adult stem cells. Cell 116: 639-648, 2004.

28. Houghton J, Stoicov C, Nomura S, Rogers AB, Carlson J, Li H, Cai X, Fox JG, Goldenring JR and Wang TC: Gastric cancer originating from bone marrow-derived cells. Science 306 : $1568-1571,2004$

29. Zhu AJ and Watt FM: Beta-catenin signalling modulates proliferative potential of human epidermal keratinocytes independently of intercellular adhesion. Development 126 2285-2298, 1999.
30. Cheng Y, Cheung AK, Ko JM, Phoon YP, Chiu PM, Lo PH, Waterman ML and Lung ML: Physiological $\beta$-catenin signaling controls self-renewal networks and generation of stem-like cells from nasopharyngeal carcinoma. BMC Cell Biol 14: 44, 2013.

31. Morel AP, Lièvre $M$, Thomas $C$, Hinkal $G$, Ansieau $S$ and Puisieux A: Generation of breast cancer stem cells through epithelial-mesenchymal transition.PLoS One 3: e2888, 2008.

32. Zhang Z, Filho MS and Nör JE: The biology of head and neck cancer stem cells. Oral Oncol 48: 1-9, 2012.

33. González-Moles MA, Bravo M, Ruiz-Avila I, Acebal F, Gil-Montoya JA, Brener S and Esteban F: Ki-67 expression in non-tumour epithelium adjacent to oral cancer as risk marker for multiple oral tumours. Oral Dis 16: 68-75, 2010.

34. Yu S, Zhang R, Liu F, Wang H, Wu J and Wang Y: Notch inhibition suppresses nasopharyngeal carcinoma by depleting cancer stem-like side population cells. Oncol Rep 28: 561-566, 2012.

35. Zhang P, Zhang Y, Mao L, Zhang Z and Chen W: Side population in oral squamous cell carcinoma possesses tumor stem cell phenotypes. Cancer Lett 277: 227-234, 2009.

36. Song J, Chang I, Chen Z, Kang M and Wang CY: Characterization of side populations in HNSCC: Highly invasive, chemoresistant and abnormal Wnt signaling. PLoS One 5: e11456, 2010.

37. Yanamoto S, Kawasaki G, Yamada S, Yoshitomi I, Kawano T, Yonezawa $\mathrm{H}$, Rokutanda S, Naruse T and Umeda M: Isolation and characterization of cancer stem-like side population cells in human oral cancer cells. Oral Oncol 47: 855-860, 2011.

38. Richard V, Nair MG, Santhosh Kumar TR and Pillai MR: Side population cells as prototype of chemoresistant, tumor-initiating cells. Biomed Res Int 2013: 517237, 2013.

39. Zhai JM, Yin XY, Hou X, Hao XY, Cai JP, Liang LJ and Zhang LJ: Analysis of the genome-wide DNA methylation profile of side population cells in hepatocellular carcinoma. Dig Dis Sci 58: 1934-1947, 2013.

40. Broadley KW, Hunn MK, Farrand KJ, Price KM, Grasso C, Miller RJ, Hermans IF and McConnell MJ: Side population is not necessary or sufficient for a cancer stem cell phenotype in glioblastoma multiforme. Stem Cells 29: 452-461, 2011

41. Guo D, Xu BL, Zhang XH and Dong MM: Cancer stem-like side population cells in the human nasopharyngeal carcinoma cell line cne- 2 possess epithelial mesenchymal transition properties in association with metastasis. Oncol Rep 28: 241-247, 2012.

42. Wei X, Dombkowski D, Meirelles K, Pieretti-Vanmarcke R, Szotek PP, Chang HL, Preffer FI, Mueller PR, Teixeira J, MacLaughlin DT and Donahoe PK: Mullerian inhibiting substance preferentially inhibits stem/progenitors in human ovarian cancer cell lines compared with chemotherapeutics. Proc Natl Acad Sci USA 107: 18874-18879, 2010.

43. Wu CP, Zhou L, Xie M, Du HD, Tian J, Sun S and Li JY: Identification of cancer stem-like side population cells in purified primary cultured human laryngeal squamous cell carcinoma epithelia. PLoS One 8: e65750, 2013.

44. Tabor MH, Clay MR, Owen JH, Bradford CR, Carey TE, Wolf GT and Prince ME: Head and neck cancer stem cells: The side population. Laryngoscope 121: 527-533, 2011

45. Mack B and Gires O: CD44s and CD44v6 expression in head and neck epithelia. PLoS One 3: e3360, 2008.

46. Keramari M, Razavi J, Ingman KA, Patsch C, Edenhofer F, Ward CM and Kimber SJ: SOX2 is essential for formation of trophectoderm in the preimplantation embryo. PLoS One 5: e13952, 2010

47. Okumura-Nakanishi S, Saito M, Niwa H and Ishikawa F: Oct-3/4 and SOX 2 regulate Oct-3/4 gene in embryonic stem cells. J Biol Chem 280: 5307-5317, 2005.

48. Evans RD, Perkins VC, Henry A, Stephens PE, Robinson MK and Watt FM: A tumor-associated beta 1 integrin mutation that abrogates epithelial dfferentiation control. J Cell Biol 160: 589-596, 2003

49. Yin AH, Miraglia S, Zanjani ED, Almeida-Porada G, Ogawa M, Leary AG, Olweus J, Kearney J and Buck DW: AC133, a novel marker for human hematopoietic stem and progenitor cells. Blood 90: 5002-5012, 1997.

50. Aruffo A, Stamenkovic I, Melnick M, Underhill CB and Seed B CD44 is the principal cell surface receptor for hyaluronate. Cell 61: 1303-1313, 1990 .

51. Felthaus O, Ettl T, Gosau M, Driemel O, Brockhoff G, Reck A, Zeitler K, Hautmann M, Reichert TE, Schmalz G and Morsczeck C: Cancer stem cell-like cells from a single cell of oral squamous carcinoma cell lines. Biochem Biophys Res Commun 407: 28-33, 2011. 
52. Faber A, Barth C, Hörmann K, Kassner S, Schultz JD, Sommer U, Stern-Straeter J, Thorn C and Goessler UR: CD44 as a stem cell marker in head and neck squamous cell carcinoma. Oncol Rep 26: 321-326, 2011.

53. Oliveira LR, Oliveira-Costa JP, Araujo IM, Soave DF, Zanetti JS, Soares FA, Zucoloto S and Ribeiro-Silva A: Cancer stem cell immunophenotypes in oral squamous cell carcinoma. J Oral Pathol Med 40: 135-142, 2011

54. Grimm M, Alexander D, Munz A, Hoffmann J and Reinert S: Is 1,25-dihydroxyvitamin D3 receptor expression a potential Achilles' heel of CD $44^{+}$oral squamous cell carcinoma cells? Target Oncol 8: 189-201, 2013.

55. Nishikawa S, Konno M, Hamabe A, Hasegawa S, Kano Y, Ohta K, Fukusumi T, Sakai D, Kudo T, Haraguchi N, et al: Aldehyde dehydrogenase high gastric cancer stem cells are resistant to chemotherapy. Int J Oncol 42: 1437-1442, 2013.

56. Clay MR, Tabor M, Owen JH, Carey TE, Bradford CR, Wolf GT, Wicha MS and Prince ME: Single-marker identification of head and neck squamous cell carcinoma cancer stem cells with aldehyde dehydrogenase. Head Neck 32: 1195-1201, 2010.

57. Krishnamurthy S, Dong Z, Vodopyanov D, Imai A, Helman JI, Prince ME, Wicha MS and Nör JE: Endothelial cell-initiated signaling promotes the survival and self-renewal of cancer stem cells. Cancer Res 70: 9969-9978, 2010.

58. Zhang Z, Dong Z, Lauxen IS, Filho MS and Nör JE: Endothelial cell-secreted EGF induces epithelial to mesenchymal transition and endows head and neck cancer cells with stem-like phenotype. Cancer Res 74: 2869-2881, 2014.

59. Richard V and Pillai MR: The stem cell code in oral epithelial tumorigenesis: 'The cancer stem cell shift hypothesis'. Biochim Biophys Acta 1806: 146-162, 2010

60. Allegra E, Trapasso S, Pisani D and Puzzo L: The role of BMI1 as a biomarker of cancer stem cells in head and neck cancer: A review. Oncology 86: 199-205, 2014

61. Zhou ZT and Jiang WW: Cancer stem cell model in oral squamous cell carcinoma. Curr Stem Cell Res Ther 3: 17-20, 2008.

62. Hayashi S, Tanaka J, Okada S, Isobe T, Yamamoto G Yasuhara R, Irie T, Akiyama C, Kohno Y, Tachikawa T and Mishima K: Lin28a is a putative factor in regulating cancer stem cell-like properties in side population cells of oral squamous cell carcinoma. Exp Cell Res 319: 1220-1228, 2013.

63. Miranda-Lorenzo I, Dorado J, Lonardo E, Alcala S, Serrano AG, Clausell-Tormos J, Cioffi M, Megias D, Zagorac S, Balic A, et al: Intracellular autofluorescence: A biomarker for epithelial cancer stem cells. Nat Methods 11: 1161-1169, 2014.

64. Kokalj Vokač N, Cizmarević B, Zagorac A, Zagradišnik B and Lanišnik B: An evaluation of SOX2 and hTERC gene amplifications as screening markers in oral and oropharyngeal squamous cell carcinomas. Mol Cytogenet 7: 5, 2014

65. He KF, Zhang L, Huang CF, Ma SR, Wang YF, Wang WM, Zhao ZL, Liu B, Zhao YF, Zhang WF and Sun ZJ: CD163 tumor-associated macrophages correlated with poor prognosis and cancer stem cells in oral squamous cell carcinoma. Biomed Res Int 2014: 838632, 2014

66. Chen C, Wei Y, Hummel M, Hoffmann TK, Gross M, Kaufmann AM and Albers AE: Evidence for epithelial-mesenchymal transition in cancer stem cells of head and neck squamous cell carcinoma. PLoS One 6: e16466, 2011.

67. Piao L, Zhang M, Datta J, Xie X, Su T, Li H, Teknos TN and Pan Q: Lipid-based nanoparticle delivery of Pre-miR-107 inhibits the tumorigenicity of head and neck squamous cell carcinoma. Mol Ther 20: 1261-1269, 2012.

68. Walter V, Yin X, Wilkerson MD, Cabanski CR, Zhao N, Du Y, Ang MK, Hayward MC, Salazar AH, Hoadley KA, et al: Correction: Molecular subtypes in head and neck cancer exhibit distinct patterns of chromosomal gain and loss of canonical cancer genes. PLoS One 8: e56823, 2014.

69. Wilbertz T, Wagner P, Petersen K, Stiedl AC, Scheble VJ, Maier S, Reischl M, Mikut R, Altorki NK, Moch H, et al: SOX2 gene amplification and protein overexpression are associated with better outcome in squamous cell lung cancer. Mod Pathol 24: 944-953, 2011

70. Hussenet T, Dali S, Exinger J, et al: SOX2 is an oncogene activated by recurrent $3 \mathrm{q} 26.3$ amplifications in human lung squamous cell carcinomas. PLoS One 5: e8960, 2010.

71. Rodriguez-Pinilla SM, Sarrio D, Moreno-Bueno G, Rodriguez-Gil Y, Martinez MA, Hernandez L, Hardisson D, Reis-Filho JS and Palacios J: Sox2: A possible driver of the basal-like phenotype in sporadic breast cancer. Mod Pathol 20: 474-481, 2007.
72. Lu W, Feng F, Xu J, et al: QKI impairs self-renewal and tumorigenicity of oral cancer cells via repression of SOX2. Cancer Biol Ther 15: 1174-1184, 2014

73. Hägerstrand D, He X, Bradic Lindh M, Hoefs S, Hesselager G, Ostman A and Nistér M: Identification of a SOX2-dependent subset of tumor - and sphere-forming glioblastoma cells with a distinct tyrosine kinase inhibitor sensitivity profile. Neuro Oncol 13: 1178-1191, 2011.

74. Bourguignon LY, Wong $G$, Earle $C$ and Chen L: Hyaluronan-CD44v3 interaction with Oct4-Sox2-Nanog promotes miR-302 expression leading to self-renewal, clonal formation, and cisplatin resistance in cancer stem cells from head and neck squamous cell carcinoma. J Biol Chem 287: 32800-32824, 2012.

75. Leis O, Eguiara A, Lopez-Arribillaga E, Alberdi MJ, Hernandez-Garcia S, Elorriaga K, Pandiella A, Rezola R and Martin AG: SOX2 expression in breast tumours and activation in breast cancer stem cells. Oncogene 31: 1354-1365, 2012.

76. Lim YC, Kang HJ, Kim YS and Choi EC: All-trans-retinoic acid inhibits growth of head and neck cancer stem cells by suppression of Wnt//-catenin pathway. Eur J Cancer 48: 3310-3318, 2012.

77. Sun Y, Han J, Lu Y, Yang X and Fan M: Biological characteristics of a cell subpopulation in tongue squamous cell carcinoma. Oral Dis 18: 169-177, 2012

78. Lee SH, Nam HJ, Kang HJ, Kwon HW and Lim YC: Epigallocatechin-3-gallate attenuates head and neck cancer stem cell traits through suppression of Notch pathway. Eur J Cancer 49: 3210-3218, 2013

79. Züllig L, Roessle M, Weber C, Graf N, Haerle SK, Jochum W, Stoeckli SJ, Moch H and Huber GF: High sex determining region Y-box 2 expression is a negative predictor of occult lymph node metastasis in early squamous cell carcinomas of the oral cavity. Eur J Cancer 49: 1915-1922, 2013.

80. Xu N, Papagiannakopoulos T, Pan G, Thomson JA and Kosik KS: MicroRNA-145 regulates OCT4, SOX2, and KLF4 and represses pluripotency in human embryonic stem cells. Cell 137: 647-658, 2009.

81. Liu T, Cheng W, Huang Y, Huang Q, Jiang L and Guo L: Human amniotic epithelial cell feeder layers maintain human iPS cell pluripotency via inhibited endogenous microRNA-145 and increased SOX2 expression. Exp Cell Res 318: 424-434, 2012.

82. Huang CF, Xu XR, Wu TF, Sun ZJ and Zhang WF: Correlation of ALDH1, CD44, OCT4 and SOX2 in tongue squamous cell carcinoma and their association with disease progression and prognosis. J Oral Pathol Med 43: 492-498, 2014.

83. Liu K, Lin B, Zhao M, Yang X, Chen M, Gao A, Liu F, Que J and Lan X: The multiple roles for SOX2 in stem cell maintenance and tumorigenesis. Cell Signal 25: 1264-1271, 2013.

84. Floor SL, Dumont JE, Maenhaut C and Raspe E: Hallmarks of cancer: Of all cancer cells, all the time? Trends Mol Med 18: 509-515, 2012.

85. Christofori G: New signals from the invasive front. Nature 441: 444-450, 2006

86. Langley RR and Fidler IJ: The seed and soil hypothesis revisited - the role of tumor-stroma interactions in metastasis to different organs. Int J Cancer 128: 2527-2535, 2011.

87. Comen EA: Tracking the seed and tending the soil: Evolving concepts in metastatic breast cancer. Discov Med 14: 97-104, 2012.

88. Comen E, Norton L and Massagué J: Clinical implications of cancer self-seeding. Nat Rev Clin Oncol 8: 369-377, 2011.

89. Nakatsugawa M, Takahashi A, Hirohashi Y, Torigoe T, Inoda S, Murase M, Asanuma H, Tamura Y, Morita R, Michifuri Y, et al: SOX2 is overexpressed in stem-like cells of human lung adenocarcinoma and augments the tumorigenicity. Lab Invest 91: 1796-1804, 2011

90. Lee HJ, Eom DW, Kang GH, Han SH, Cheon GJ, Oh HS, Han KH, Ahn HJ, Jang HJ and Han MS: Colorectal micropapillary carcinomas are associated with poor prognosis and enriched in markers of stem cells. Mod Pathol 26: 1123-1131, 2013.

91. $\mathrm{Hu} \mathrm{H}$, Chang DT, Nikiforova MN, Kuan SF and Pai RK: Clinicopathologic features of synchronous colorectal carcinoma: A distinct subset arising from multiple sessile serrated adenomas and associated with high levels of microsatellite instability and favorable prognosis. Am J Surg Pathol 37: 1660-1670, 2013

92. Han X, Fang X, Lou X, Hua D, Ding W, Foltz G, Hood L, Yuan Y and Lin B: Silencing SOX2 induced mesenchymal-epithelial transition and its expression predicts liver and lymph node metastasis of CRC patients. PLoS One 7: e41335, 2012.

93. Abd El-Maqsoud NM and Abd El-Rehim DM: Clinicopathologic implications of EpCAM and SOX2 expression in breast cancer. Clin Breast Cancer 14: e1-e9, 2014. 
94.Li X, Xu Y, Chen Y, Chen S, Jia X, Sun T, Liu Y, Li X, Xiang R and Li N: SOX2 promotes tumor metastasis by stimulating epithelial-to-mesenchymal transition via regulation of WNT/ $\beta$-catenin signal network. Cancer Lett 336: 379-389, 2013.

95.Li X, Chen S, Sun T, Xu Y, Chen Y, Liu Y, Xiang R and Li N: The transcriptional regulation of SOX2 on FOXA1 gene and its application in diagnosis of human breast and lung cancers. Clin Lab 60: 909-918, 2014

96. Yang F, Gao Y, Geng J, Qu D, Han Q, Qi J and Chen G: Elevated expression of SOX 2 and FGFR 1 in correlation with poor prognosis in patients with small cell lung cancer. Int J Clin Exp Pathol 6: 2846-2854, 2013.

97. Tang XB, Shen XH, Li L, Zhang YF and Chen GQ: SOX2 overexpression correlates with poor prognosis in laryngeal squamous cell carcinoma. Auris Nasus Larynx 40: 481-486, 2013.

98. Schröck A, Göke F, Wagner P, Bode M, Franzen A, Braun M, Huss S, Agaimy A, Ihrler S, Menon R, et al: Sex determining region Y-box 2 (SOX2) amplification is an independent indicator of disease recurrence in sinonasal cancer. PLoS One 8: e59201, 2013.
99. González-Márquez R, Llorente JL, Rodrigo JP, García-Pedrero JM, Álvarez-Marcos C, Suárez C and Hermsen MA: SOX2 expression in hypopharyngeal, laryngeal, and sinonasal squamous cell carcinoma. Hum Pathol 45: 851-857, 2014.

100. Qiao B, He B, Cai J and Yang W: The expression profile of Oct4 and SOX2 in the carcinogenesis of oral mucosa. Int J Clin Exp Pathol 7: 28-37, 2014.

101. Lu Y, Futtner C, Rock JR, Xu X, Whitworth W, Hogan BL and Onaitis MW: Evidence that SOX 2 overexpression is oncogenic in the lung. PLoS One 5: e11022, 2010. 